\title{
Mediastinoscopy: a diagnostic procedure in hilar and paratracheal lymphadenopathy
}

\author{
J. R. Mikhail
}

\author{
Central Middlesex Hospital and MRC Tuberculosis and Chest Diseases \\ Research Unit, Brompton Hospital, London, S.W.3
}

\begin{abstract}
Summary
Mediastinoscopy, in the skilled hands of a thoracic surgeon, is a safe, cosmetically accepted procedure with negligible complications, less than that reported in many series of scalene node biopsies.

It has the advantage of yielding a much higher rate of diagnostic tissue, in all instances over $90 \%$. In the cases of tuberculosis it enabled an organism to be isolated and sensitivities obtained.

It has also revealed a group of cases with findings, a further study of which may increase our understanding, assessment and management of patients presenting with hilar and/or paratracheal lymphadenopathy.
\end{abstract}

IN recent years there have been a number of publications from which the value of mediastinoscopy as a diagnostic procedure has become increasingly evident. Carlens in 1959 described the technique of mediastinoscopy and this procedure has been widely adopted in many centres throughout the world.

In 1966 this technique was introduced at Central Middlesex Hospital for the investigation of hilar and paratracheal lymphadenopathy. The method adopted was that described by Carlens in 1950 and Nohl-Oser in 1965; mediastinoscopy was first performed by Mr J. K. Ross, subsequently by Mr J. W. Jackson, Sir Thomas Holmes Sellors and now currently by Miss Mary Shepherd. We are greatly indebted to our surgical colleagues for their help in this investigation.

\section{Technique}

General anaesthesia is always employed. Anaesthesia is induced with thiopentone, suxamenthonium and oxygenation prior to passing an oral cuff tube. A topical spray of lignocaine $4 \%$ is applied to the vocal cords and trachea and a $2 \%$ water-soluble lignocaine gel is applied to the cuff tute. Anaesthesia is maintained with nitrous oxide, oxygen and halothane $0 \cdot 5-1 \%$ using a semi-open circuit. Gallamine $40-80 \mathrm{mg}$ is used as a relaxant. The patient is positioned on the operating table with the neck extended and the head turned to the right, the

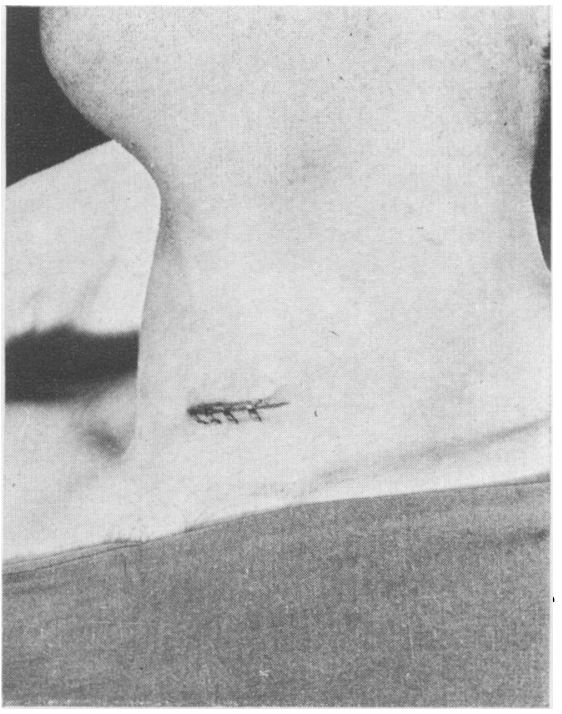

FIG. 1. Wound on completion of mediastinoscopy.

operator standing to the patient's left. A $3 \mathrm{~cm}$ skincrease incision is made approximately $2 \mathrm{~cm}$ above the supra-sternal notch extending equally either side of the mid-line (Fig. 1). This is deepened through the platysma and the pre-tracheal fascia to expose the trachea below the isthmus of the thyroid gland. Occasionally a suitable lymph node for biopsy is found here or just deep to the pre-tracheal fascia. Once the plane deep to the pre-tracheal fascia has been entered, the tunnel into the mediastinum is developed with the index finger, which is then passed downwards and backwards to the right behind the aortic arch into the right paratracheal region. In this area enlarged lymph nodes can sometimes be palpated and on occasions mobilized by the exploring finger. A straight-bladed laryngoscope is then introduced into the tunnel and the paratracheal lymph nodes located under direct vision (Fig. 2). With experience, the greyish coloured lymph nodes are readily distinguished from other structures such as the azygos vein. A long aspirating needle is used 


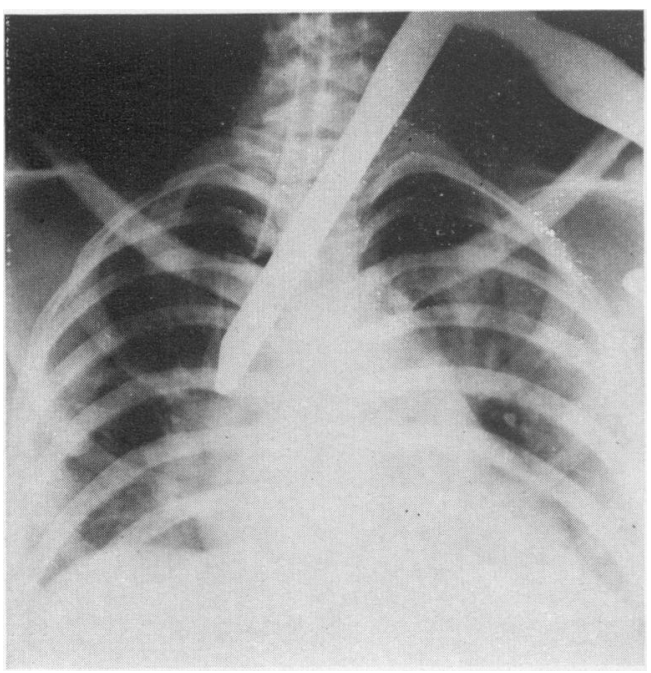

FIG. 2. Mediastinoscope in position.

to differentiate between the vascular structures and lymph nodes. Blunt nosed bronchial biopsy forceps are used to break gently through the thin fascia overlying the lymph node which is then biopsied. Mobile nodes are sometimes removed whole. In the series described, serious bleeding never complicated the biopsy procedure. The wound is closed without drainage.

This procedure, in our opinion and that of our surgical colleagues, should only be carried out by an experienced thoracic surgeon and in these circumstances has met with minimal complications.

\section{Value of mediastinoscopy}

One might ask why do we go to the trouble of mediastinoscopy in assessment of these patients? Many people feel that the clinical presentation and radiological findings are so characteristic as to leave no room for doubt in the diagnosis. Whilst we recognize the fully blown Löfgren syndrome we do not entirely agree and a few X-rays illustrate the dilemma in which we find ourselves. The first (Fig. 3) is the X-ray of a Jamaican male aged 25 years who had been in Britain for 6 years. The chest X-ray shows a large right paratracheal gland and bilateral hilar lymphadenopathy. The gland removed at mediastinoscopy showed caseating granulomata. Kveim test was negative. Direct examination of the gland did not reveal acid-fast bacilli but the culture grew human type tubercle bacilli sensitive to standard chemotherapy.

The next X-ray (Fig. 4) is that of a female Kenya Indian aged 20 years who had been in this country for 1 year. Chest X-ray shows bilateral hilar lymphadenopathy. The gland removed at mediastinoscopy showed caseating granulomata and tubercle bacilli of human type sensitive to standard drugs were isolated on culture.

The next X-ray (Fig. 5) is that of a male Indian patient aged 36 who had been in this country for 3 years. Chest X-ray showed bilateral hilar and right paratracheal gland enlargement. The gland produced at mediastinoscopy showed caseating granulomata and tubercle bacilli of human type sensitive to standard therapy were isolated on culture.

The next X-ray (Fig. 6) is a male Kenya Indian aged 38 years who presented with right paratracheal gland enlargement. The gland removed at mediastinoscopy was caseating and tubercle bacilli were isolated on culture. They were of human type and sensitive to standard drugs. Tubercle bacilli were also isolated from his sputum on culture and despite chemotherapy he has subsequently developed a tuberculous dorsal spine.

The next four X-rays (Figs. 7, 8, 9 and 10) are cases of confirmed sarcoidosis who are tuberculinnegative with non-caseating mediastinal glands and whose Kveim tests are positive and without treatment have shown spontaneous resolution.

I would now like to present four case histories of difficult diagnostic problems. The first is a 22 -yearold Irish girl who had been in England for 9 months. She gave a 3-month history of cough. No abnormality was detected on clinical examination. The chest X-ray (Fig. 11) showed enlargement of the right hilar and paratracheal glands. Her Mantoux $10 \mathrm{~T} . \mathrm{U}$. was strongly positive $-15 \mathrm{~mm}$ in diameter. A mediastinal gland (Fig. 12) showed non-caseating granulomata with central necrosis. Acid-fast rods were seen on Ziehl-Neelsen examination of the gland. A diagnosis of pulmonary tuberculosis was made and she was commenced on tuberculous chemotherapy. A subsequent culture of the gland was negative. Serial X-rays (Figs. 13 and 14) showed diminution in the size of the hilar glands and reticulation has appeared in the mid-zone. The possibility of a ruptured tuberculous gland was considered. The patient has been well and symptomless and retrospectively it seems likely that this patient has in fact sarcoidosis. Her Kveim test has been performed and is positive. Her tuberculin test is still strongly positive.

The next case is that of a 30-year-old Pakistani man who had been in the country for 5 years. He was X-rayed in 1968 and found to have a normal $\mathrm{X}$-ray. He re-appeared 3 years later with a history of a cough for 2 years. Nothing abnormal was found on examination. The X-ray (Fig. 15) shows enlargement of the right paratracheal glands. Heaf test was negative. The gland removed at mediastinoscopy showed non-caseating granulomata. Despite the negative tuberculin test, in view of his nationality and the X-ray appearances, a diagnosis of probable 


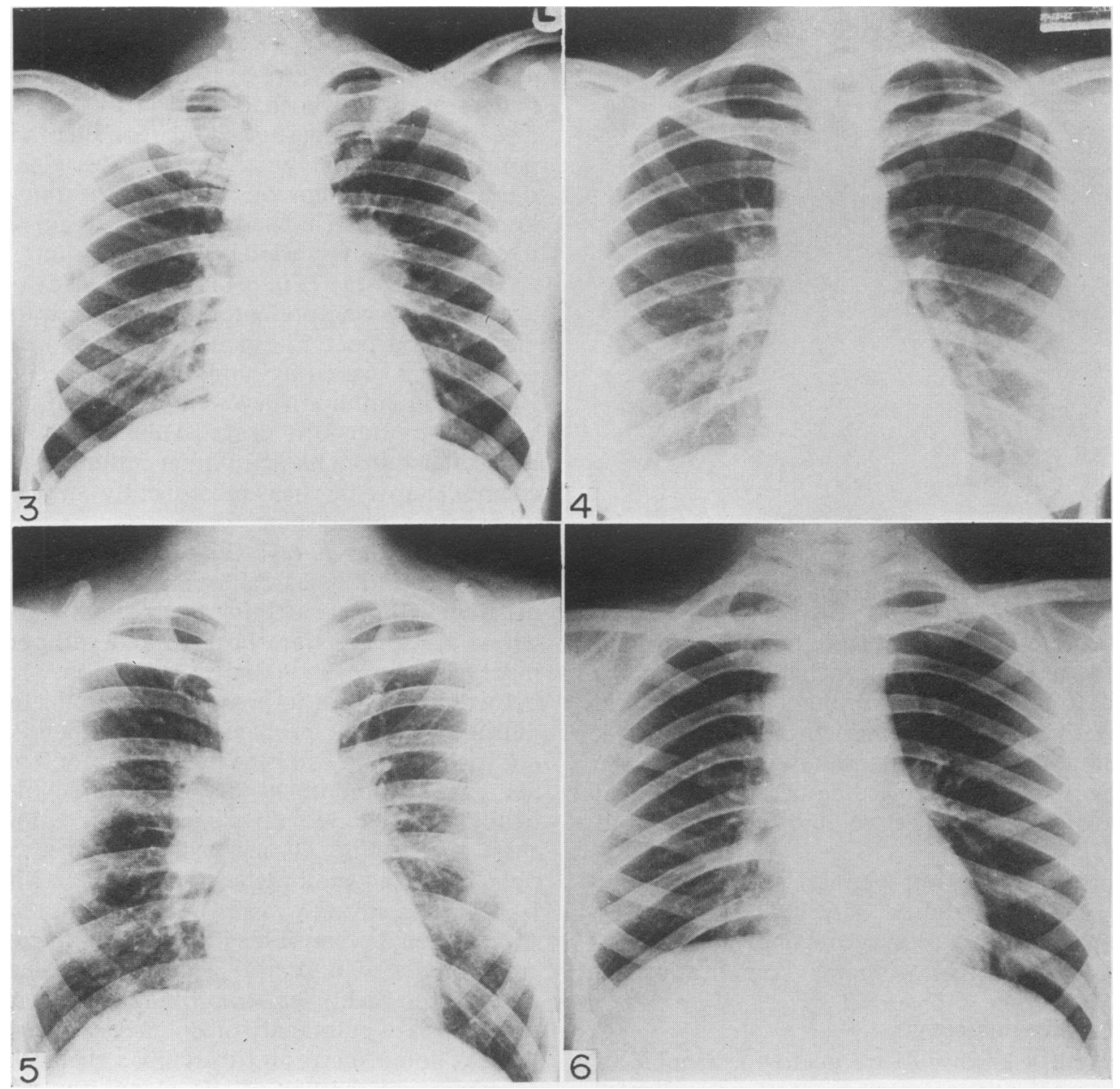

FIGs. 3-6. Tuberculous mediastinal lymphadenopathy.

primary tuberculosis was made and he was commenced on tuberculous chemotherapy. Subsequent X-ray (Fig. 16) shows regression of the glands. A repeat Mantoux 10 T.U. was negative. A Kveim test performed 2 months later was positive (Fig. 17). This man appears to be a case of Asian sarcoidosisan infrequently reported finding.

The next two cases illustrate an even greater dilemma in the assessment of hilar lymphadenopathy. The first case is that of a 38-year-old Fijian man who had been in England for 8 years. He presented to the neurosurgeons with raised intracranial pressure, bilateral papilloedema and haemorrhage in the left disc. The right plantar was extensor. The electroencephalogram showed no focal lesion but a diffuse abnormality suggestive of encephalitis.
Skull X-ray showed evidence of raised intra-cranial 7 pressure. Carotid angiograms showed ventricular 3 dilatation presumably due to obstruction of the aqueduct. At operation the obstruction in the aqueduct was overcome with slight resistance to the rubber catheter. A biopsy of the vermis was taken and was normal. No evidence of a tuberculoma was 옥 found. Chest X-ray (Fig. 18) showed right paratracheal gland enlargement. Mantoux 10 T.U. was strongly positive $-10 \mathrm{~mm}$ in diameter. A gland was removed at mediastinoscopy and this showed granulomata with central areas of softening. Culture of the gland grew tubercle bacilli and they were also isolated by guinea-pig inoculation. These organ- $\underset{<}{2}$ isms were of human type, resistant to PAS but sensitive to other tuberculous drugs. The Kveim test 


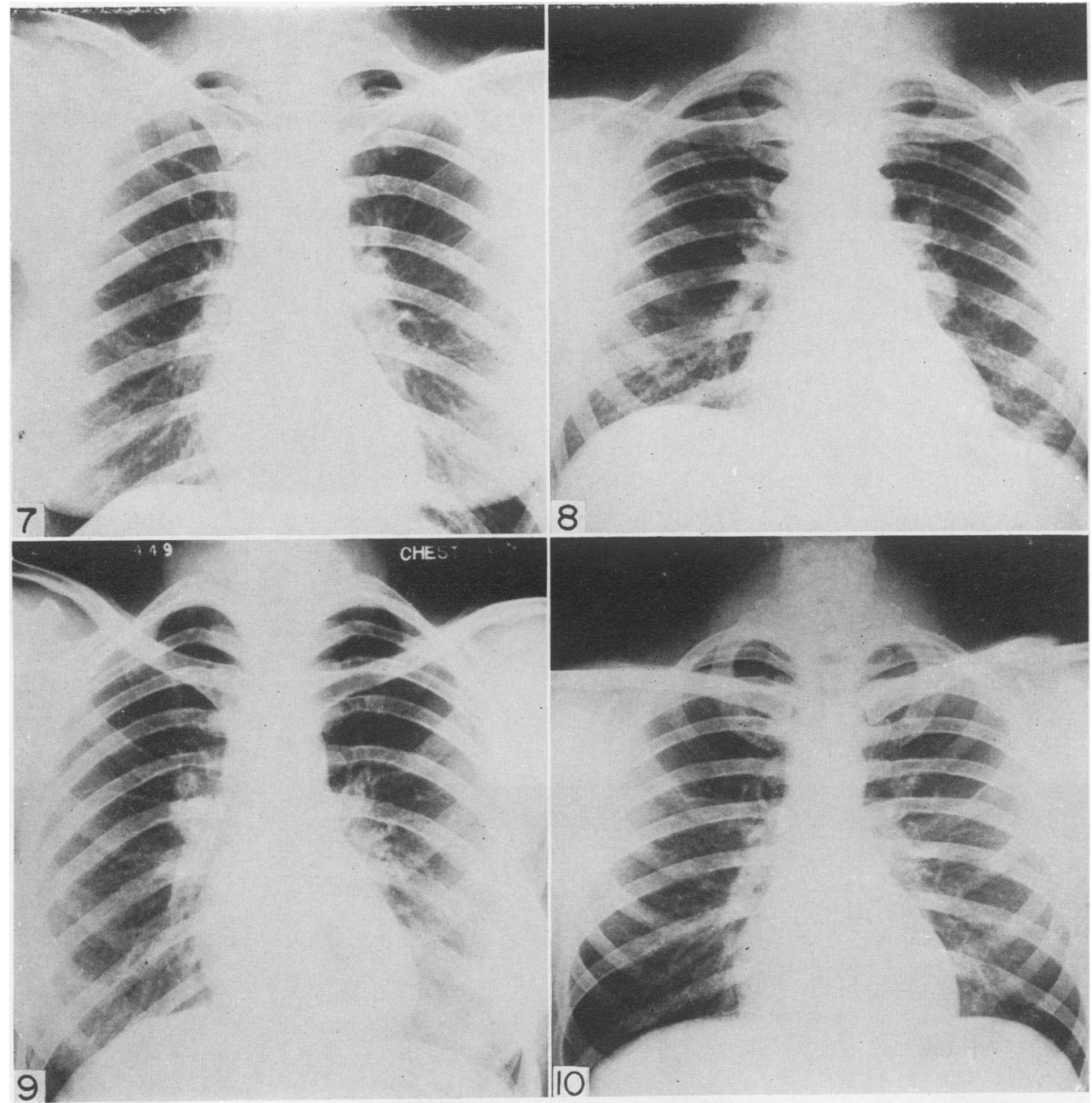

Figs. 7-10. Sarcoid mediastinal lymphadenopathy.

was positive (Fig. 19). He was treated with tuberculous chemotherapy with slow resolution of the glandular enlargement. He remains well on completion of 2 years' chemotherapy and his chest X-ray is now within normal limits.

The last case is that of a Kenya Indian aged 24 who had been in this country for 5 years, examined as a contact of his brother who has extensive bilateral sputum-positive tuberculosis. This patient was found to have a right paratracheal gland enlargement (Fig. 20). His Mantoux 10 T.U. was strongly positive. A gland removed at mediastinoscopy showed caseating granulomata and culture of the gland revealed human type tubercle bacilli sensitive to standard chemotherapy. He has been treated with tuberculous chemotherapy and on this regime the gland slowly resolved. His Kveim test on serial section is positive.

These latter two cases are instances of an increasing diagnostic problem: Could they (i) both have tuberculosis due to mycobacterial infection and sarcoidosis caused by a hypothetical unknown agent? Are they (ii) as Dr Harold Israel has reported recently, in the New England Journal of Medicine, cases of glandular tuberculosis with a positive Kveim test; or (iii) sarcoid reaction to mycobacterial infection; or (iv) a form of hybrid disease? In a small number of cases of glandular tuberculosis so far tested $50 \%$ appear to be positive. This is a subject 

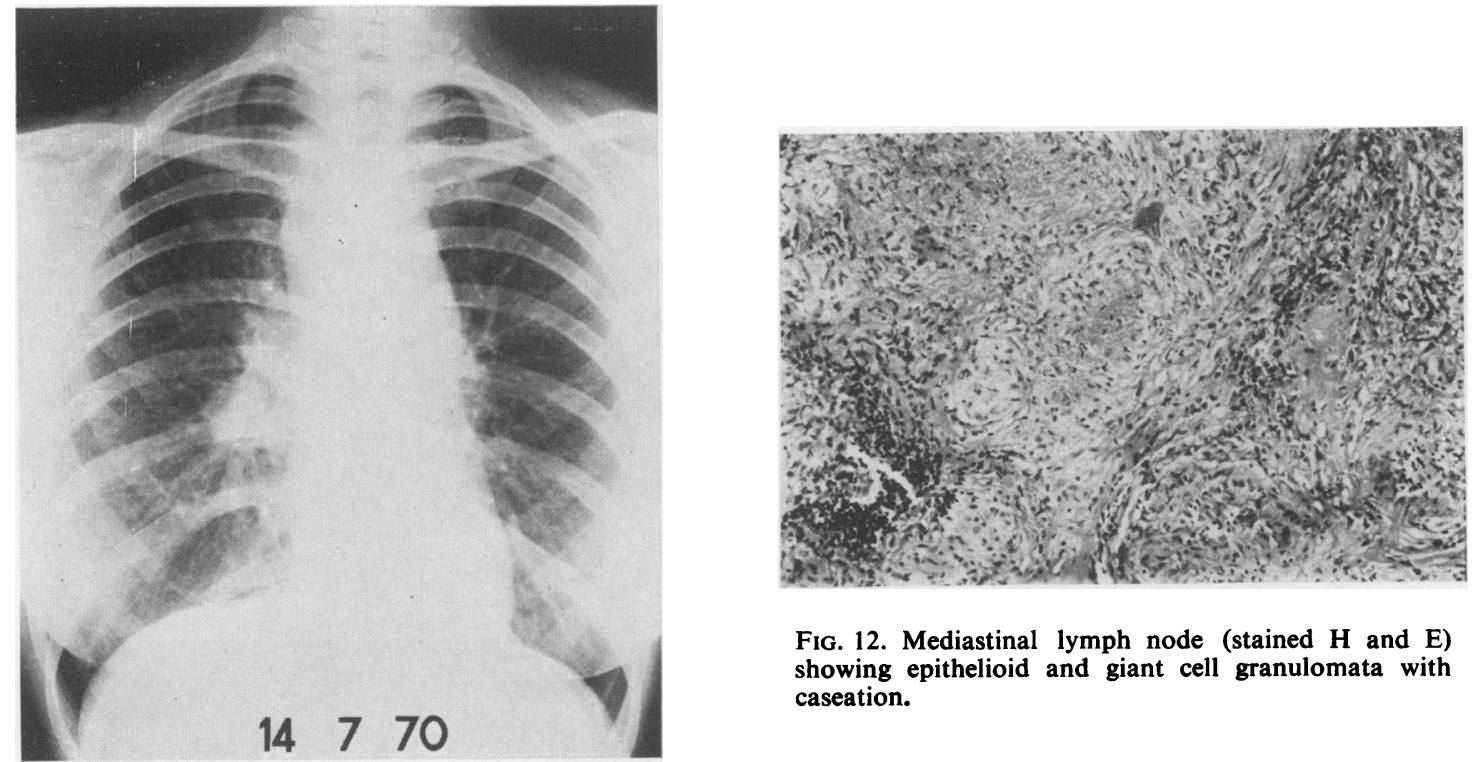

FIG. 12. Mediastinal lymph node (stained $\mathbf{H}$ and $E$ ) showing epithelioid and giant cell granulomata with caseation.

FIG. 11. Chest radiograph showing right hilar and paratracheal lymphadenopathy.

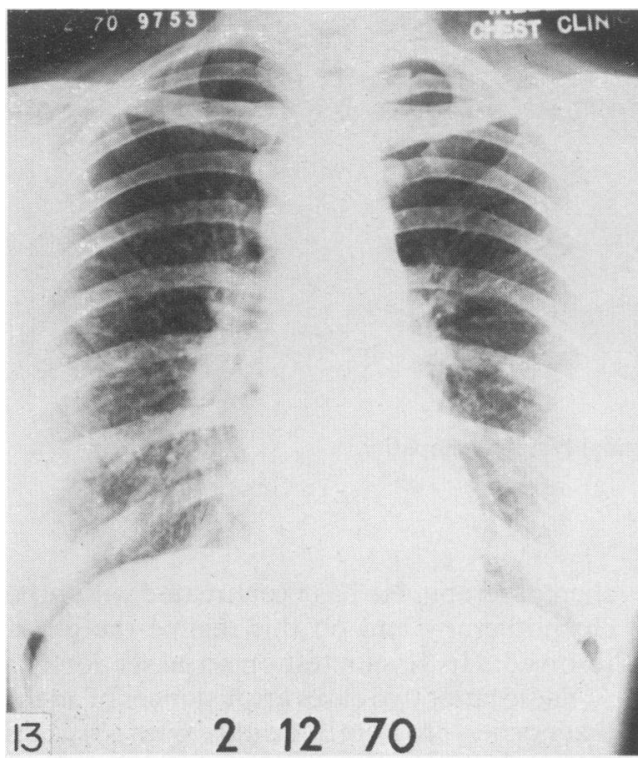

FIG. 13. Chest radiograph showing regression of hilar glands and development of reticulation.

of further investigation which we would not like to comment upon further with the limited information at present available and pending further assessment.

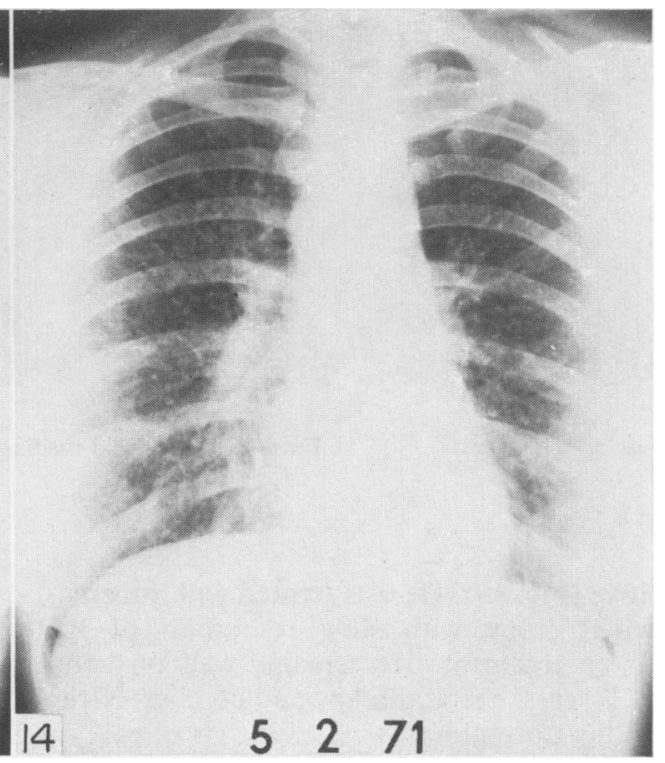

FIg. 14. Chest radiograph 2 months later showing further reticulation.

\section{Analysis of results}

In analysing our cases of mediastinoscopy, the results to date are as shown in Table 1. 


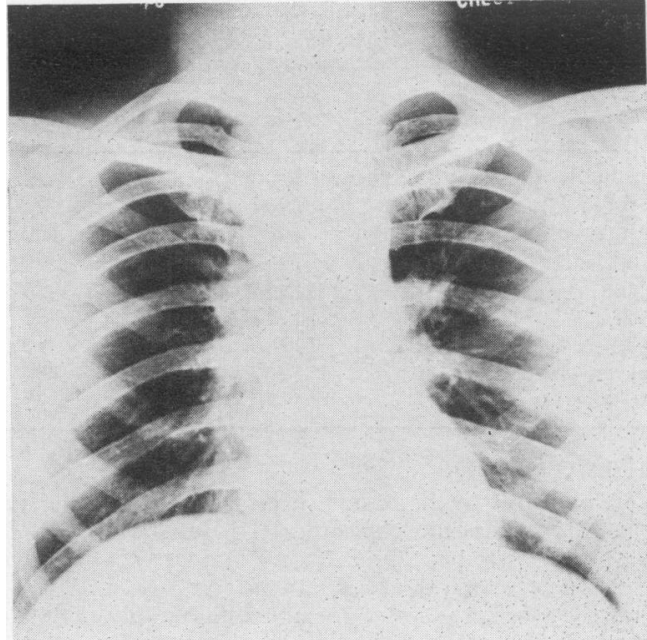

FIG. 15. Chest radiograph-right paratracheal lymphadenopathy.

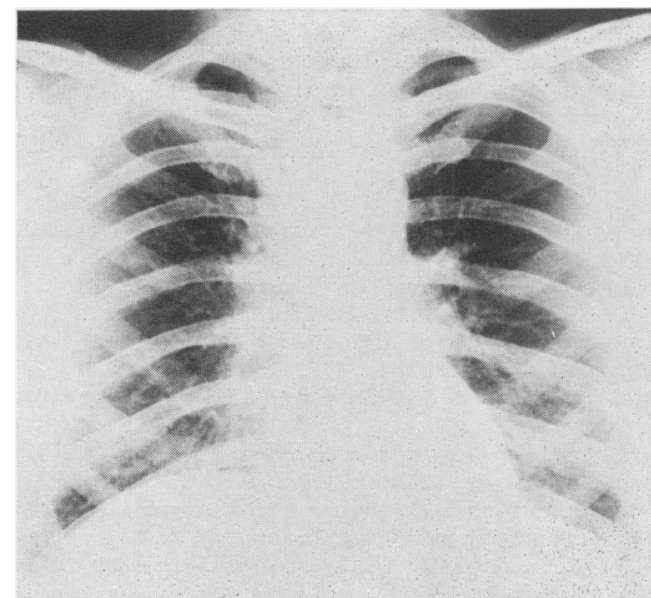

Fig. 16. Chest radiograph 16 months later showing regression of paratracheal glands.

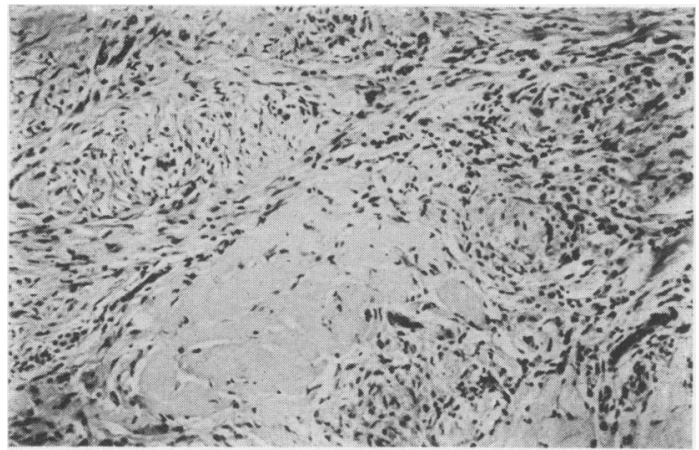

FIG. 17. Positive Kveim test (stained $\mathbf{H}$ and E).

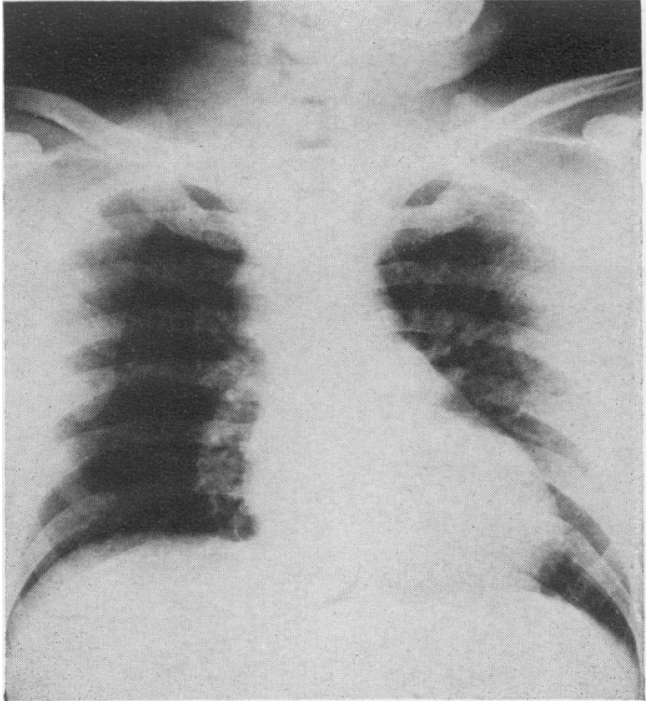

FIG. 18. Chest radiograph-right paratracheal lymphadenopathy.

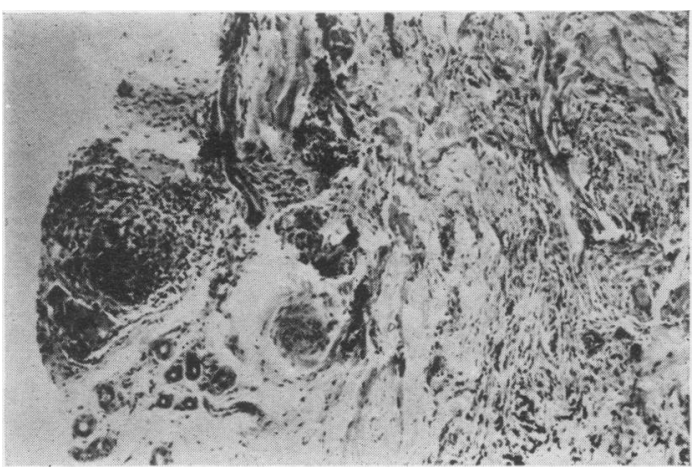

Fig. 19. Positive Kveim test (stained H \& E).

In the 130 cases of sarcoidosis who have had mediastinoscopy diagnostic tissue has been obtained in $121(93 \%)$ and you will see that this figure compares favourably with other series shown in Table 2.

Of the 179 mediastinoscopies undertaken, 99\% of the cases of tuberculosis have produced diagnostic tissue and $100 \%$ in those cases with malignant disease. In the last twenty-two cases of glandular tuberculosis, diagnostic tissue was obtained in twenty-one cases. In nineteen of these tubercle bacilli of human type were isolated on culture of the gland. In one case cited earlier acidfast rods were seen on direct examination but did not grow. In the other case a caseating gland was obtained tubercle bacilli were not grown on culture of the gland but a positive sputum culture was sub- 
sequently obtained. In two cases resistant organisms -one to PAS and the other to isoniazid-were isolated.

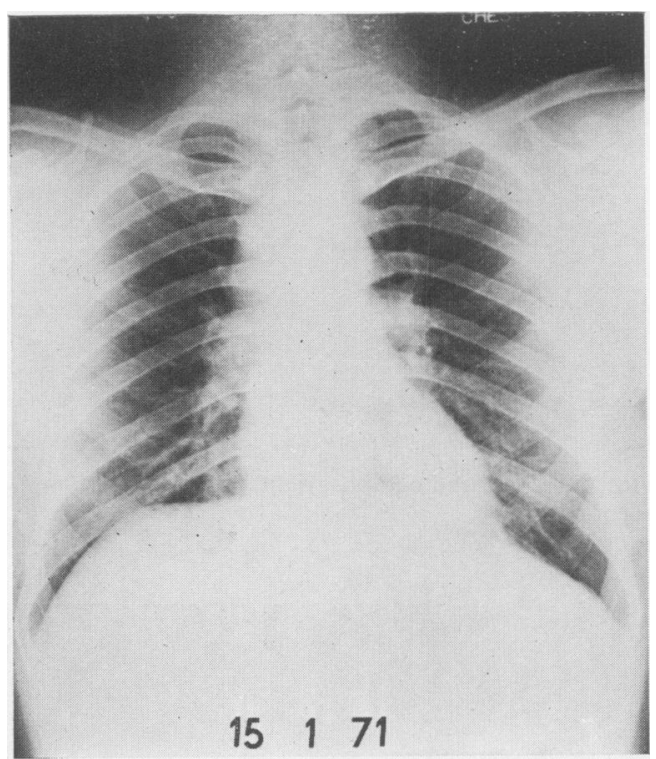

FIG. 20. Chest radiograph-right paratracheal lymphadenopathy.

TABLE 1. Mediastinoscopies (1966-70)

\begin{tabular}{lccc}
\hline & No. of & \multicolumn{2}{c}{$\begin{array}{c}\text { Diagnostic } \\
\text { tissue obtained }\end{array}$} \\
\cline { 3 - 4 } & patients & No. & $\%$ \\
\hline Sarcoidosis & 130 & 121 & 93 \\
Tuberculosis & 37 & 36 & 99 \\
Malignant disease & 12 & 12 & 100 \\
Total & 179 & 169 & 95 \\
\hline
\end{tabular}

TABLE 2. Sarcoidosis-comparison of mediastinoscopy series

\begin{tabular}{lccc}
\hline \multicolumn{1}{c}{ Author } & Year & $\begin{array}{c}\text { No. of } \\
\text { patients }\end{array}$ & $\begin{array}{c}\% \\
\text { positive }\end{array}$ \\
\hline Löfgren, Snellman \& Stavenow & 1963 & 34 & 94 \\
Friedel et al. & 1964 & 30 & 100 \\
Bergh, Rydbern \& Schersten & 1964 & 33 & 100 \\
Palva & 1964 & 28 & 96 \\
Carlens & 1965 & 123 & 96 \\
Jepsen & 1966 & 43 & 85 \\
Nielsen \& Olsen & 1966 & 121 & 95 \\
Maassen & 1967 & 115 & 100 \\
Present series & 1970 & 130 & 93 \\
\hline
\end{tabular}

\section{Acknowledgments}

We would like to thank our surgical colleagues who performed the mediastinoscopies and Dr Jennifer Dyson for help with the histology; Dr E. Taylor and Dr D. McSwiggan for the bacteriological examinations. We are indebted to Mr A. G. Booker A.R.P.s. for the photographs contained herein.

\section{References}

Bergh, N.P., Rydbern, B. \& Schersten, T. (1964) Mediastinal exploration by the technique of Carlens. Diseases of the Chest, 64, 399.

Carlens, E. (1950) Mediastinoscopy: A method for inspec-o tion and tissue biopsy in the superior mediastinumo Diseases of the Chest, 36, 343.

CARLENS, E. (1965) Mediastinoscopy. Annals of Otology Rhinology and Laryngology, 74, 1102.

Friedel, H., DorscheId, H.O., Kirsch, M. \& MuCke, To (1964) Die bedeutung der bronchoskopie und mediastinoskopie fur die sarkoidose-diagnostik. Zeitschrift für Tuber气 kulose und Erkrankungen der Thoraxorgane, 121, 152.

ISRAEL, H.L. \& GoldSTEIN, R.A. (1971) Relation of Kveim Antigen Reaction to Lymphadenopathy. New England Journal of Medicine, 284, 345.

JEPSEN, O. (1966) Mediastinoscopy. Einar Munksgaard Forlag, Copenhagen.

Lofgren, S., Snellman, B. \& Stavenow, S. (1963) Biopsier for diagnosis vid sarkoidos. Nordisk Medicin, 69, 409.

MAASSEN, W. (1967) Ergebnisse und bedeutung der Mediastinoskopie. Springer-Verlag, Berlin.

Nielsen, E.G. \& OlSen, H. (1960) Mediastinoscopy. Danish Medical Bulletin, 13, 193.

NoHL-Oser, H.C. (1965) Mediastinoscopy. British Medical Journal, 1, 1167.

Palva, T. (1964) Mediastinal sarcoidosis. Acta oto-laryngologica, Supplement, 188, 258.

Ross, J.K., Mikhail, J.R., DruRy, R.A.B., Levis, R.D. \& Mitchell, D.N. (1970) Mediastinoscopy. Thorax, 25, 312. 